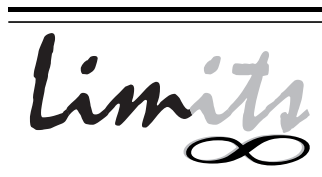

J. Math. and Its Appl.

ISSN : $1829-605 \mathrm{X}$

Vol. 7, No. 2, November 2010, 47-55

\title{
INDEKS KEMAMPUAN PROSES BERDASARKAN PROPORSI PERSESUAIAN UNTUK DISTRIBUSI NON NORMAL
}

\author{
Laksmi P Wardhani ${ }^{1}$, Resty Z Fahrida, Nur Hasanah \\ Jurusan Matematika FMIPA ITS Surabaya \\ ${ }^{1}$ wmarbun@indo.net.id
}

\begin{abstract}
Abstrak
Indeks Kemampuan proses adalah suatu alat untuk menganalisa kemampuan proses produksi apakah sesuai dengan spesifikasi yang diberikan. Indeks $C_{p}, C_{p k}, C_{p m}$, dan $C_{p m k}$ adalah indeks yang sering digunakan untuk mengukur kemampuan proses dengan berdasarkan proporsi bagian yang tidak sesuai (Proportion non Conforming) dan pada indeks ini data diasumsikan berdistribusi Normal.

Indeks Kemampuan proses berdasarkan bagian yang sesuai (proportion of conforming) yaitu $C_{p c}$ dapat mengatasi kelemahankelemahan dari indeks kemampuan proses yang berdasarkan Proportion non Conforming diatas dimana data tidak harus berdistribusi Normal. Dalam tulisan ini dibahas analisis tentang indeks $C_{p c}$ dengan menggunakan asumsi berdistribusi Non Normal yaitu distribusi Poisson dan distribusi Eksponensial berikut estimasi dari $C_{p c}$ yaitu $\widehat{C}_{p c}$.

Katakunci: Indeks kemampuan proses, distribusi Poisson, distribusi Eksponensial, MLE, limit kepercayaan.
\end{abstract}




\section{Pendahuluan}

Pengendalian Kualitas terhadap suatu produk menjadi hal yang penting dalam dunia industri disebabkan adanya berbagai penyimpangan yang sering terjadi dalam suatu proses produksi. Berbagai penyimpangan terjadi apabila produk yang dihasilkan tidak sesuai dengan dengan spesifikasi yang telah ditetapkan. Setelah proses produksi terken-dali maka dilakukan analisis kemampuan proses, yaitu analisi tentang kemampuan proses untuk memproduksi suatu produk apakah sesuai dengan batas-batas spesifikasi yang telah ditetapkan perusahaan. Analisis kemampuan proses memerlukan indeks kemampuan proses untuk mengukur dan menganalisis potensial dan performa dari suatu proses produksi.

Indeks kemampuan proses sering digunakan adalah $C_{p}, C_{p k}, C_{p m}$, dan $C_{p m k}$ dengan dasar perhitungannya berdasarkan proportion of non conforming (bagian yang tidak sesuai) . Kelemahan indeks indeks tersebut adalah peubah acak yang digunakan harus ber-distribusi Normal dan batas spesifikasi bawah (BSB ) dan batas spesifikasi atas(BSA) harus diketahui terlebih dahulu.

Telah diusulkan sebuah indeks kemampuan proses yang baru untuk mengatasi kelemahan dari indeks-indeks sebelumnya, yaitu indeks $C_{p c}$. Indeks $C_{p c}$ adalah indeks kemampuan proses yang berdasarkan proportion of conforming (bagian yang sesuai). Salah satu kelebihan indeks $C_{p c}$ adalah dapat digunakan untuk data yang berdistribusi non Normal, baik diskrit ataupun kontinu. Pada tulisan ini akan dianalisis indeks $C_{p c}$ untuk asumsi distribusi diskrit yaitu distribusi Poisson dan distribusi kontinu yaitu distribusi Eksponensial. Analisa yang akan dilakukan adalah estimator dari $C_{p c}$ dan limit kepercayaannya.

\section{Indeks $C_{p c}$}

Indeks $C_{p c}$ yaitu indeks kemampuan proses berdasarkan proportion of conforming (bagian yang sesuai) atau jumlah unit produksi yang memenuhi satu atau beberapa spesifikasi dari proses produksi tersebut/tidak cacat. Indeks $C_{p c}$ didefinisikan sebagai berikut [4]:

$$
C_{p c}=\frac{1-p_{0}}{1-p}
$$


Dengan $p$ : bagian yang sesuai

$p_{0}$ : proses minimun yang diijinkan.

Nilai $p_{0}$ adalah 0,9973 , yaitu luasan dari sebaran alamiah dari suatu proses yang besarnya $6 \sigma$. Nilai-nilai dibawah atau diatas 0,9973 diijinkan, namun hasil yang diperoleh menjadi tidak maksimum.

Selain itu, indeks $C_{p c}$ juga didefinisikan sebagai berikut:

$$
C_{p c}=\min \left\{\frac{p_{0}^{L}}{p_{1}}, \frac{p_{0}^{U}}{p_{2}}\right\}
$$

Dengan $p_{1}=P(X<U), U$ batas spesifikasi atas.

$$
p_{2}=P(X>L), L \text { batas spesifikasi bawah. }
$$

Sedangkan $p_{0}^{L}$ dan $p_{0}^{U}$ adalah bagian proses yang cacat (tidak sesuai) yang dapat diterima sesuai dengan batas spesifikasi bawah dan atas yang diberikan.

Nilai minimum yang yang diperkenankan dalam proporsi yang sesuai $p_{0}$ secara intuisi dikehendaki yang mendekati nilai 1 . Walaupun nilai $p_{0}$ tidak spesifik, tetapi nilai 0,9973 lebih senang dipilih karena mempunyai sifatsifat yang mendekati satu dan proses rata-rata tepat berlokasi pada titik tengah spesifikasi $M=(L+U) / 2$ dan nilai tersebut merupakan nilai standar dari Indeks Kemampuan Proses [4]. Dalam tulisan ini, supaya memudahkan diasumsikan nilai $p_{0}=0,9973$. Jadi indeks $C_{p c}$ dalam persamaan (1) dapat ditulis kembali dalam bentuk berikut:

$$
C_{p c}=\frac{0,0027}{1-p}
$$

Dengan demikian analisa indeks ini selanjutnya dapat dimodifikasi sesuai asumsi nilai $p_{0}$ lain yang diinginkan, sedangkan tulisan ini analisa selanjutnya akan memakai persamaan (2).

Pengujian nilai yang berbeda untuk nilai $p$, akan menghasilkan nilai $C_{p c}$ sebagai berikut:

(a) Jika nilai $p=0,9973$, maka nilai indeks $C_{p c}=1$

(b) Jika nilai $p>0,9973$, maka nilai indeks $C_{p c}>1$

(c) Jika nilai $p>0,9973$, maka nilai indeks $C_{p c}<1$ 
Satu-satunya parameter yang tidak diketahui dalam indeks $C_{p c}$ adalah $p$, nilai $p$ tergantung pada bentuk distribusi yang diguanakan dalam proses produksi, dan dapat diestimasi dalam bentuk sampel acak dalam proses yang diuji. Hasil estimasinya dinotasikan dalam bentuk $\widehat{p}$, sehingga estimator indeks $C_{p c}$ adalah

$$
\widehat{C}_{p c}=\frac{0,0027}{1-\widehat{p}}
$$

\section{Analisa inferensia indeks $C_{p c}$ untuk proses berdistribusi Poisson}

Dalam bagian ini indeks $C_{p c}$ dianalisa dalam kasus dimana proses produksi yang diberikan berkarakteristik distribusi Poisson dengan parameter $\lambda$. Jika nilai $U$ diketahui, maka indeks dinotasikan dengan $C_{\mathrm{pcu}}$, demikian juga jika nilai $L$ yang diberikan, maka indeks dinotasikan dengan $C_{\mathrm{pcl}}$. Indeks $C_{\text {pcu }}$ didefinisikan sebagai [2], [5]:

$$
C_{\mathrm{pcu}}=\frac{0,0027}{1-p_{1}}, \quad \text { dengan } p_{1}=P(X<U)
$$

Indeks $C_{\mathrm{pcl}}$ didefinisikan sebagai

$$
C_{\mathrm{pcl}}=\frac{0,0027}{1-p_{2}}, \quad \text { dengan } p_{2}=P(X>L)
$$

dengan $p_{1}$ dan $p_{2}$ merupakan Fungsi Distribusi Kumulatif (CDF) dari distribusi Poisson dengan parameter $\lambda$, jadi

$$
p_{1}=P(X \leq U-1)=\sum_{x=0}^{U-1} \frac{e^{-\lambda} \lambda^{x}}{x !}
$$

Karena adanya hubungan antara Distribusi Poisson dengan distribusi Gamma maka persamaan (6) dapat ditulis sebagai,

$$
p_{1}=P(X \leq U-1)=P\left(\chi_{2 U}^{2}>2 \lambda\right)
$$

Dengan $\chi_{2 U}^{2}$ distribusi chi-kuadrat dengan derajat kebebasan $2 U$. Oleh karena itu berdasarkan sifat-sifat probabilitas Persamaan (4) dapat ditulis kembali sebagai

$$
C_{\mathrm{pcu}}=\frac{0,0027}{P\left(\chi_{2 U}^{2}<2 \lambda\right)}
$$


Dengan cara yang serupa, indeks $C_{\mathrm{pcl}}$ dapat ditulis kembali dalam bentuk

$$
C_{\mathrm{pcl}}=\frac{0,0027}{P\left(\chi_{2(L+1)}^{2}>2 \lambda\right)}
$$

\subsection{Estimasi $C_{\mathrm{pcu}}$ dan $C_{\mathrm{pcl}}$ untuk proses distribusi Poisson}

Jika parameter $\lambda$ tidak diketahui maka harus diganti dengan estimasinya seperti diketahui MLE(Maximum Likelihood Estimation) dari parameter $\lambda$ untuk $n$ sampel acak $\left(X_{1}, X_{2}, \ldots, X_{n}\right)$ dari distribusi Poisson adalah mean (rata-rata dari sampel) yaitu $\widehat{\lambda}=\bar{X}$. Jadi estimator untuk $C_{\mathrm{pcu}}$ dan $C_{\mathrm{pcl}}$ masing-masing adalah [2], [5]:

$$
C_{\mathrm{pcu}}=\frac{0,0027}{P\left(\chi_{2 U}^{2}<2 \widehat{\lambda}\right)} \quad \text { dan } \quad C_{\mathrm{pcl}}=\frac{0,0027}{P\left(\chi_{2(L+1)}^{2}>2 \widehat{\lambda}\right)}
$$

Untuk menganalisan apakah estimator untuk $C_{\mathrm{pcu}}$ dan $C_{\mathrm{pcl}}$ yaitu $\widehat{C}_{\mathrm{pcu}}$ dan $\widehat{C}_{\text {pcl }}$ merupakan estimator yang tak bias, dilihat terlebih dahulu nilai harapan dari estimator tersebut.

$$
E\left(\widehat{C}_{\mathrm{pcu}}\right)=C_{\mathrm{pcu}} \times \frac{1}{1-\left[e^{-n \lambda}\left(n \lambda+(n \lambda)^{-2}\right)\right]}
$$

Sehingga estimator tak bias dari $C_{\mathrm{pcu}}$ adalah $b_{n} \times \widehat{C}_{\mathrm{pcu}}$ dengan $b_{n}$ sebagai faktor koreksi, dan $b_{n}=1-\left[e^{-n \lambda}\left(n \lambda+(n \lambda)^{-2}\right)\right]$.

\subsection{Limit kepercayaan untuk indeks $C_{p c}$}

Selang kepercayaan $100(1-\alpha) \%$ untuk indeks $C_{p c}$ memunyai lebar selang sebagai berikut:

$$
P\left(L \leq C_{p c} \leq U\right)=1-\alpha
$$

Untuk membangun selang kepercayaan, dilakukan pendekatan dengan distribisi sampling Chi-Kuadrat. Jika diberikan $n$ sampel acak $\left(X_{1}, X_{2}, \ldots, X_{n}\right)$ dengan $X_{i} \sim P O I(\lambda)$ maka $Y=\sum_{i=1}^{n} x_{i}$ juga berdistribusi Poisson dengan parameter $n \lambda$. Karena ada hubungan antara distribusi Poisson dengan distribusi Chi-Kuadrat seperti pada awal tulisan diatas, selang kepercayaan $100(1-\alpha) \%$ untuk indeks $n \lambda$ adalah

$$
\frac{1}{2} \chi_{2 Y}^{2}, \alpha<n \lambda<\frac{1}{2} \chi_{2(Y+1)}^{2}, 1-\alpha
$$


Dengan cara yang serupa, didapat limit kepercayaan atas $100(1-\alpha) \%$ untuk $n \lambda$ yaitu

$$
P\left(n \lambda<\frac{1}{2} \chi_{2(Y+1), 1-\alpha}^{2}\right)=1-\alpha
$$

atau

$$
P\left(2 \lambda<\frac{\chi_{2(Y+1), 1-\alpha}^{2}}{n}\right)=1-\alpha
$$

Selang kepercayaan $100(1-\alpha) \%$ untuk $C_{\text {pcl }}$ didapat dari persamaan (8) dan (11) didapat adalah

$$
\frac{0,0027}{P\left(\chi_{2 U}^{2}<\frac{\chi_{2(Y+1), 1-\alpha}^{2}}{n}\right)}
$$

Dengan cara yang similar didapat selang kepercayaan 100(1- $\alpha) \%$ untuk $C_{\text {pcu }}$ sebagai berikut:

$$
\frac{0,0027}{1-P\left(\chi_{2(L+1)}^{2}<\frac{\chi_{2 Y, \alpha}^{2}}{n}\right)}
$$

\section{Analisis inferensia indeks $C_{p c}$ untuk proses berdistribusi Eksponensial}

Dalam bagian ini indeks $C_{p c}$ dianalisa dalam kasus dimana proses produksi yang diberikan berkarakteristik distribusi Eksponensial dengan parameter $\theta$.

Distribusi Eksponensial diasumsikan sangat beralasan karena dipakai pada uji reliabilitas tentang uji hidup suatu produk . Karena distribusi ini non normal maka akan dilihat selang kepercayaannya satu sisi seperti pada distribusi Poisson pada subbab 3.

Dengan menggunakan batasan seperti persamaan (4) dan (5) didapat masing-masing indeks $C_{\mathrm{pcu}}$ dan $C_{\mathrm{pcl}}$ pada distribusi Eksponensial adalah $[3],[4]:$

$$
C_{\mathrm{pcu}}=\frac{0,0027}{e^{-\theta U}}
$$

dan

$$
C_{\mathrm{pcl}}=\frac{0,0027}{1-e^{-\theta L}}
$$

Dengan CDF untuk $X \sim \operatorname{EXP}(\theta)$ adalah $F(x, \theta)=1-e^{-\theta x}, x>0$. 


\subsection{Estimasi $C_{\mathrm{pcu}}$ dan $C_{\mathrm{pcl}}$ untuk proses distribusi ekspo- nensial}

Selanjutnya dicari estimator untuk $C_{\mathrm{pcu}}$ dan $C_{\mathrm{pcl}}$ dari asumsi distribusi Eksponensial dengan cara mencari estimator untuk parameter $\theta$. M L E untuk $\theta$ adalah $\widehat{\theta}=\frac{1}{X}$, sehingga diperoleh estimator untuk $C_{\mathrm{pcu}}$ dan $C_{\mathrm{pcl}}$ masing-masing adalah,

$$
\widehat{C}_{\mathrm{pcu}}=\frac{0,0027}{e^{-\widehat{\theta} U}}=\frac{0,0027}{e^{-\frac{U}{X}}}
$$

dan

$$
\widehat{C}_{\mathrm{pcl}}=\frac{0,0027}{1-e^{-\widehat{\theta} L}}=\frac{0,0027}{1-e^{-\frac{L}{\bar{X}}}}
$$

Dengan menggunakan pdf (probability density functions) dari distribusi Eksponential, metode transformasi satu-satu [1] dan $Y=\sum_{i=1}^{n} X_{i} \sim$ $\operatorname{GAM}(\theta, n)$ didapat distribusi dari $\widehat{C}_{\mathrm{pcu}}$ dan $\widehat{C}_{\mathrm{pcl}}$.

Jika $W=\widehat{C}_{c p u}$ maka $W=0,0027 e^{\bar{X}^{-1} U}$ dan pdf dari $W$ yaitu

$$
f_{W}(w)=\frac{(\theta n U)^{n}}{\Gamma(n)}(\ln w+5,9145)^{-n-1} w^{-1} e^{(-\theta n U) /(\ln w+5,9145)},
$$

untuk $0,0027<w<\infty$. Jika $V=\widehat{C}_{c p l}$, maka dengan cara yang similar seperti $W$ didapat pdf untuk $V$ adalah [3]:

$f_{V}(v)=\frac{(\theta n L)^{n}}{\Gamma(n)}\left(-\ln \left(\frac{1-0,0027}{v}\right)\right)^{-n-1} e^{(\theta n L) /(\ln (1-0,0027 / v)} \frac{0,0027}{v^{2}-0,0027 v}$,

untuk $0,0027<w<\infty$.

\subsection{Limit Kepercayaan untuk indeks $C_{p c}$}

Selang kepercayaan 100(1- $\alpha) \%$ untuk indeks $C_{p c}$ mempunyai lebar selang sebagai berikut:

$$
P\left(L \leq C_{p c} \leq U\right)=1-\alpha
$$

Untuk membangun selang kepercayaan, dilakukan pendekatan dengan distribusi sampling. Jika diberikan $n$ sampel acak $\left(X_{1}, X_{2}, \ldots, X_{n}\right)$ dengan $X_{i} \sim \operatorname{EXP}(\theta)$ maka $Y=\sum_{i=1}^{n} X_{i} \sim G A M(\theta, n)$ dan $Z=\theta Y$ didapat 
$Z \sim G A M(1, n)$ terlihat $\mathrm{Z}$ tidak bergantung dari parameter $\theta$. Limit kepercayaan bawah $100(1-\alpha) \%$ untuk $\theta$ diperoleh dengan menggunakan percentil $\alpha$ dari distribusi $Z$ yiatu $c_{1}$, sehingga dengan melihat persamaan (14) dan (15) didapat

$$
\begin{aligned}
& P\left(Z>c_{1}\right)=P\left(\theta>\frac{c_{1}}{Y}\right)=P\left(\frac{c_{1}}{Y}<\theta\right)=P\left(e^{\frac{-U c_{1}}{Y}}<e^{-\theta U}\right)= \\
& P\left(C_{\mathrm{pcu}}>\frac{0,0027}{e^{\frac{-U c_{1}}{Y}}}\right)=1-\alpha
\end{aligned}
$$

Jadi limit kepercayaan bawah $100(1-\alpha) \%$ untuk $C_{\text {pcu }}$ adalah

$$
\frac{0,0027}{e^{\frac{-U c_{1}}{\sum x_{i}}}}
$$

Dengan cara yang similar didapat limit kepercayaan bawah 100(1- $\alpha) \%$ untuk $C_{\mathrm{pcl}}$ adalah $\frac{0,0027}{1-e^{\frac{-L c_{2}}{\sum x_{i}}}}$ dengan $c_{2}$ adalah percentile $1-\alpha$ dari distribusi $\mathrm{Z}$.

\section{Kesimpulan}

Dari kajian diatas terlihat bahwa indeks kemampuan Proses $C_{p c}$ banyak menanggulangi beberapa kekurangan dari indeks kemampuan Proses yang lama antara lain hanya diasumsikan untuk distribusi normal, sedangkan indeks $C_{p c}$ dapat digunakan untuk distribusi Non-Normal baik untuk proses diskrit seperti distribusi Poisson dan kontinyu seperti distribusi Eksponensial.

Estimasi Parameter dari Indeks $C_{p c}$ untuk kedua distribusi cukup dengan melihat MLE dari parameter distribusi tersebut, sedangkan limit kepercayaan hanya untuk satu sisi saja.

\section{Pustaka}

[1] Bain, L.J. dan Engelhardt, M., Introduction to Probability and Mathematical Statistics, 2nd edition, Duxbury Press, California, 1991. 
[2] Fahrida, R. Z., Kajian Indeks Kemampuan Proses $C_{p c}$ dengan menggunakan asumsi distribusi Poisson, Tugas Akhir, Jurusan Matematika FMIPA ITS, 2008

[3] Nur, H, Kajian Indeks Kemampuan Process $C_{p c}$ dengan menggunakan asumsi distribusi Eksponensial Tugas Akhir. Jurusan Matematika FMIPA ITS, 2009.

[4] Perakis, M. dan Xekalaki, E. 2002. A Process Capability Index that it based on the Proportion of Conformance. Journal Statistical Computation and Simulation, 2002, Vol 72(9), pp. 707-718.

[5] Perakis, M. dan, Xekalaki, E., A Process Capability Indeks For Discrete Processes. Journal Statistical Computation and Simulation, March 2005, vol 75 No.3, pp 175-187. 